\title{
KEPEMIMPINAN KOLEKTIF DI PONDOK PESANTREN (STUDI MULTISITUS DI PP. TEBUIRENG JOMBANG, PP. BAHRUL ULUM TAMBAKBERAS JOMBANG DAN PP. MAMBAUL MA'ARIF DENANYAR JOMBANG)
}

\author{
Devi Pramitha \\ Fakultas Ilmu Tarbiyah dan Keguruan Universitas Islam \\ Negeri Maulana Malik Ibrahim Malang \\ e-mail: phe2_90@yahoo.co.id
}

\begin{abstract}
Abstrak: Pondok pesantren merupakan lembaga pendidikan Islam yang unik, tidak saja karena keberadaannya yang sudah sangat lama, tetapi juga karena kultur, metode dan jaringan yang diterapkan oleh lembaga agama tersebut berbeda dengan lembaga pendidikan Islam lainnya. Besarnya peranan pondok pesantren dalam pemberdayaan masyarakat tentunya tidak bisa lepas dari peranan kiai sebagai pemilik sekaligus sebagai pemimpin pesantren dalam menggerakkan komunitas pesantren. Dalam memimpin sebuah pondok pesantren, Kiai memiliki karakteristik kepemimpinan yang berbeda-beda antara satu dengan yang lain, hal tersebut disesuaikan pula dengan karakteristik pondok pesantren yang dipimpinnya. Dewasa ini memang kepemimpinan pesantren yang terjadi tidak lagi menerapkan kepemimpinan tunggal, dan organisasi pesantren pun telah dimasukkan dalam bentuk yayasan. Dengan gejala baru ini, maka organisasi pesantren menjurus kearah impersonal, tanpa mengurangi peranan kiai sebagai pemimpin tertinggi, maka kepemimpinan mengarah pada pola kolektif, sesuai dengan hierarkhi kepemimpinan sebuah organisasi yayasan.
\end{abstract}

Kata kunci: Kepemimpinan Kolektif, Pondok Pesantren

\begin{abstract}
Islamic Boarding School is a unique Islamic educational institution, not only because of its existence which has been very long, but also because the culture, methods and networks applied by religious institutions are different from other Islamic educational institutions. The magnitude of the role of boarding school in community empowerment certainly can not be separated from the role of kiai as the owner as well as the leader of pesantren in moving the pesantren community. In leading a boarding school, Kiai has leadership characteristics that vary from one to another, it is also adapted to the characteristics of the boarding school he leads. Today it is true that the leadership of pesantren does not apply single leadership, and pesantren organization has been included in the form of foundation. With this new phenomenon, the pesantren organization leads impersonally, without reducing the kiai's role as the supreme leader, then leadership leads to a collective pattern, in accordance with the hierarchy of leadership of a foundation organization.
\end{abstract}

Keyword: Collective Leadership, Islamic Boarding School 
Devi Pramitha - Kepemimpinan Kolektif di Pondok Pesantren (Studi Multisitus di PP. Tebuireng Jombang, PP. Bahrul Ulum Tambakberas Jombang dan PP. Mambaul Ma'arif Denanyar Jombang)

\section{PENDAHULUAN}

Membicarakan masalah kepemimpinan memang tidak akan pernah habisnya bahkan masih tetap saja menarik untuk dibahas dan diteliti. Hal tersebut karena kepemimpinan dapat dilihat dari sisi manapun seseorang memandang dan mengulas masalah tersebut dalam suatu objek kajian. Bila kepemimpinan dikaji dalam perspektif politik maka akan melahirkan pandangan yang berbeda bila dikaji dalam perspektif ekonomi, begitu pula jika dikaji dalam perspektif manajemen pendidikan. Kepemimpinan yang berhasil di abad globalisasi menurut Dave Ulrich adalah: "Merupakan perkalian antara kredibilitas dan kapabilitas." Kredibilitas adalah ciri-ciri yang ada pada seorang pemimpin seperti kompetensi-kompetensi, sifat-sifat, nilainilai dan kebiasaan-kebiasaan yang bisa dipercaya baik oleh bawahan maupun oleh lingkungannya. Sedangkan kapabilitas adalah kemampuan pemimpin dalam menata visi, misi dan strategi serta dalam mengembangkan sumber-sumber daya manusia untuk kepentingan memajukan organisasi dan atau wilayah kepemimpinannya. (Veithzal Rivai, 2013)

Pondok pesantren merupakan lembaga pendidikan Islam yang unik, tidak saja karena keberadaannya yang sudah sangat lama, tetapi juga karena kultur, metode dan jaringan yang diterapkan oleh lembaga agama tersebut berbeda dengan lembaga pendidikan Islam lainnya. Peranan pondok pesantren sendiri di Indonesia cukup besar dalam membangun masyarakat, hal ini dapat dilihat betapa besar kiprah dunia pesantren dalam mempertahankan bangsa dan Negara dari tangan penjajah selama berabad-abad yang kemudian berpuncak pada fatwa "Resolusi Jihad" pada Oktober 1945 yang dikeluarkan oleh KH. Hasyim Asy'ari pendiri PP. Tebuireng Jombang dan juga pendiri organisasi masyarakat terbesar Islam yakni, Nahdlatul 'Ulama (NU). Besarnya peran yang dimainkan oleh pondok pesantren tersebut bukan suatu kebetulan, tetapi ada nilai-nilai yang mendasarinya. Owens mengatakan dimensi soft yang berpengaruh terhadap kinerja individu dan organisasi, yaitu nilai-nilai (values), keyakinan (beliefs), budaya (culture), dan norma perilaku. (Stephen P. Robbins, 2003)

Besarnya peranan pondok pesantren dalam pemberdayaan masyarakat tentunya tidak bisa lepas dari peranan kiai sebagai pemilik sekaligus sebagai pemimpin pesantren dalam menggerakkan komunitas pesantren. Sehingga keberadaan sosok kiai sebagai pemimpin pondok pesantren selalu menjadi hal yang unik untuk diteliti, hal tersebut dikarenakan tugas dan fungsi kiai yang tidak hanya 
Devi Pramitha - Kepemimpinan Kolektif di Pondok Pesantren (Studi Multisitus di PP. Tebuireng Jombang, PP. Bahrul Ulum Tambakberas Jombang dan PP. Mambaul Ma'arif Denanyar Jombang)

sekedar memimpin saja, tetapi juga menyusun kurikulum, membuat sistem evaluasi, menentukan tata tertib lembaga sampai pada menata kehidupan seluruh komunitas pondok pesantren serta membina masyarakat. Dengan demikian, pertumbuhan suatu pondok pesantren sangat tergantung pada kemampuan pribadi kiainya, terlebih pada masa yang intensitas dan frekuensi perubahan yang sangat tinggi seperti pada abad ke-21 ini yang selain harus menggunakan manajemen yang baik juga diperlukan kapasitas dan kualifikasi kepemimpinan yang handal. (Zamakhsyari Dhofier, 1994)

Dalam penelitian ini, peneliti menggunakan kategorisasi pesantren berdasarkan model penyelenggaraan pendidikan dan pola manajerial kelembagaan, yaitu kategorisasi pondok pesantren semimodern yang menggunakan kepemimpinan kolektif dalam melakukan manajerial kelembagaan. Dewasa ini memang kepemimpinan pesantren yang terjadi tidak lagi menerapkan kepemimpinan tunggal, dan organisasi pesantren pun telah dimasukkan dalam bentuk yayasan. Dengan gejala baru ini, maka organisasi pesantren menjurus kearah impersonal, tanpa mengurangi peranan kiai sebagai pemimpin tertinggi, maka kepemimpinan mengarah pada pola kolektif, sesuai dengan hierarkhi kepemimpinan sebuah organisasi yayasan. Dalam hal ini menunjukkan bahwa kelangsungan eksistensi pesantren tidak lagi bergantung kepada kiai sebagai pemimpin tertingginya secara manunggal, tetapi kiai juga mendelegasikan kepemimpinannya kepada bawahannya.

Pondok Pesantren Tebuireng, Pondok Pesantren Bahrul Ulum Tambakberas dan Pondok Pesantren Mambaul Ma'arif Denanyar ketiga pondok pesantren ini menjadi menarik untuk diteliti karena ketiga pesantren tersebut didirikan oleh para pendiri organisasi Islam terbesar di Indonesia yakni Nahdlatul Ulama dan menjadikan nilai ahlu as-sunnah wa al-jama'ah sebagai pondasi dasar di pesantren, selain itu gaya kepemimpinan yang diterapkan hingga saat ini juga sama-sama menggunakan kepemimpinan kolektif hanya saja bentuk dan struktur organisasinya memiliki sedikit perbedaan.

\section{METODE PENELITIAN}

Penelitian tentang Kepemimpinan Kolektif di Pondok Pesantren (Studi Multisitus di PP. Tebuireng Jombang, PP. Bahrul Ulum Tambakberas Jombang, dan PP. Mambaul Ma'arif Denanyar Jombang) ini merupakan suatu penelitian yang dapat dikategorikan sebagai penelitian kualitatif. Dalam implementasinya, penelitian ini dilakukan dengan menggunakan pendekatan studi kasus dan rancangan studi 
Devi Pramitha - Kepemimpinan Kolektif di Pondok Pesantren (Studi Multisitus di PP. Tebuireng Jombang, PP. Bahrul Ulum Tambakberas Jombang dan PP. Mambaul Ma'arif Denanyar Jombang)

multisitus. Dalam melaksanakan penelitian ini, penelitian mengumpulkan data menggunakan wawancara, observasi dan dokumentasi di tiga tempat. Mengingat penelitian ini merupakan jenis penelitian studi kasus dengan menggunakan rancangan studi multi situs, maka dalam menganalisis data dilakukan dua tahap, yaitu: (1) analisis data situs tunggal (individual site), dan (2) analisis data lintas situs (cross site analysis).

\section{HASIL PENELITIAN}

Perspektif kepemimpinan kolektif-kolegial yang diterapkan di pondok pesantren adalah kepemimpinan bersama para masyâyîkh (dewan kiai sepuh) dari garis kekerabatan (kinship/dzurriyyah) dalam suatu organisasi di pondok pesantren. Kepemimpinan kolektif-kolegial ini mendukung terhadap teori kepemimpinan yang relevan di masa modern ini. Kepemimpinan sebagai sebuah perilaku dari individu yang memimpin aktivitas-aktivitas suatu kelompok ke suatu tujuan (shared goal) yang ingin dicapai bersama (collective). Lebih jelas lagi, Abu Sinn mendefinisikan kepemimpinan sebagai sebuah sistem dan bukanlah unsur tunggal yang memberikan pengaruh kepada orang lain, melainkan ia juga dipengaruhi oleh pendapat masyarakat, karena seorang pemimpin adalah bagian dari anggota masyarakat (jamâ'ah) yang saling berkontribusi, bertukar pendapat dan pengalaman, serta bersama-sama berusaha mewujudkan tujuan kolektif. (Abu Sinn, 2006)

Perspektif kepemimpinan kolektif-kolegial di kedua pesantren sebagaimana hasil penelitian ini, kiranya telah menjawab kekhawatiran masyarakat terhadap sistem kepemimpinan pesantren selama ini, sebagaimana pandangan A'la, bahwa selama ini manajemen (kepemimpinan) pesantren (meski tidak semua), dikelola seadanya dengan kesan menonjol pada penanganan individual dan bernuansa kharismatik. (Abd. A'la, 2006)

Perilaku kepemimpinan kolektif-kolegial di pondok pesantren Tambakberas dan pondok pesantren Denanyar kian meyakinkan peneliti terhadap transformasi yang telah diperankan kiai sebagai bentuk perubahan (silent revolution) yang diyakini sebagai pengaruh spirit keagamaan. Hal ini telah diprediksikan Gus Dur bahwa pada relasi sosio kultural kiai dan masyarakat terdapat relasi-peran kreatif kiai sebagai pelopor perubahan sosial (agent of change). Dengan kapasitasnya, kiai mampu menawarkan agenda perubahan yang dianggapnya sesuai dengan kebutuhan nyata masyarakat yang dipimpinnya. Perkembangan peran sosial kiai dalam konteks pesantren secara kualitatif saat ini, merupakan bagian tradisi, budaya, 
Devi Pramitha - Kepemimpinan Kolektif di Pondok Pesantren (Studi Multisitus di PP. Tebuireng Jombang, PP. Bahrul Ulum Tambakberas Jombang dan PP. Mambaul Ma'arif Denanyar Jombang)

dan perilaku para pemimpinnya untuk mempertahankan hak hidup kumunitasnya yang ditempa dengan spirit keagamaan yang dahsyat.

Pada Pondok Pesantren Bahrul Ulum Tambak Beras Jombang dan Pondok Pesantren Mambaul Ma'arif Denanyar Jombang terdapat majelis pengasuh dalam struktur organisasi yang secara fungsional adalah untuk pembinaan terhadap pengurus harian. Majelis pengasuh ini mempunyai tugas-tugas utama, yaitu; (a) menyusun Garis-Garis Besar Kebijakan (GBK) pesantren dan yayasan, (b) meningkatkan koordinasi, konsolidasi, dan kerja sama, baik secara internal maupun eksternal pesantren, (c) mengambil kebijakan, (d) mengontrol pelaksanaan program dan kebijakan, serta (e) membina Sumber Daya Manusia (SDM) pesantren secara integral.

Sedangkan kedudukan dewan pengawas sebagai expetio dari lembaga pertimbangan pesantren. Sebagai badan pertimbangan dewan pengawas mempunyai tugas: (a) sebagai lembaga pengawasan, (b) sebagai lembaga konsultasi biro-biro pesantren, (c) sebagai bagian dari pengurus yayasan, (d) menyampaikan saran-saran dan sumbangan pemikiran guna kepentingan penyusunan rencana program kerja dan Anggaran Pendapatan Belanja Pesantren (APBP), (e) melaksanakan tugas-tugasnya sesuai dengan ketentuan yang berlaku, dan (f) menyusun Rancangan Anggaran Pendapatan dan Belanja Pesantren (RAPBP) dan program kerja tahunan. Posisi dewan pengawas inilah yang tidak terdapat pada Pondok Pesantren Mambaul Ma'arif Denanyar Jombang.

Selanjutnya untuk pengurus harian baik di PPBU maupun di PPMA mempunyai tugas; (a) menyusun program kerja pengurus untuk masa bakti empat tahun di PPBU dan lima tahun di PPMA, (b) menyusun RAPBP dalam setiap tahun, (c) melaksanakan program kerja yang telah disahkan oleh majelis pengasuh, (d) menjatah dana pembiayaan kebutuhan dan keperluan tugas sesuai dengan alokasi APBP, (e) berhak mengambil kebijakan dalam melaksanakan tugasnya sepanjang tidak bertentangan dengan program kerja pesantren, (f) melaporkan pelaksanaan program kerja dan realisasi APB-PPS kepada majelis pengasuh serta mengajukan rencana program kerja tahunan dan RAPBP dalam setiap akhir tahun, dan (g) menandatangani suratsurat yang dialamatkan keluar dan ke dalam pesantren sesuai dengan tugas dan bidang masing-masing pengurus harian.

Berdasarkan pernyataan tersebut, dapat ditafsirkan bahwa fungsi masingmasing lembaga di pesantren yang dikelola dengan 
kepemimpinan kolektif-kolegial berjalan lebih dinamis dan fungsional sesuai dengan pembagian tugas yang telah ditetapkan dalam perencanaan secara administratif. Pembagian tugas yang jelas dan terarah sebagaimana dalam kepemimpinan kolektif-kolegial di atas, maka pondok pesantren dalam penelitian ini telah menganut sistem manajemen perencanaan terbuka. Salah satu ciri sistem perencanaan terbuka adalah organisasi memiliki diferensiasi atau spesialisasispesialisasi, di mana dalam organisasi pendidikan ada bagian kepengurusan, bagian pengajaran, dan bagian kepegawaian. Masingmasing bagian ini masih dapat dipecah menjadi bagian-bagian unit yang lebih kecil.

Perilaku kepemimpinan kolektif-kolegial di pesantren yang direpresentasikan dari majelis pengasuh dapat diasumsikan sebagai perilaku kepemimpinan demokratis. Hal ini karena kiai tidak memimpin pesantren secara individual, melainkan memimpin dengan beberapa kiai lainnya secara kolektif. Hal ini, seperti ditegaskan Syarqawi Dhofir, bahwa kekuasaan kiai tidak terpusat pada satu figur kiai, melainkan ada dalam kepemimpinan kolektif, yang berwujud dewan pimpinan. (Syarqawi Dhofir, 2004) Relevan kiranya jika hasil penelitian ini disandingkan dengan hasil penelitian Rensis Likert menunjukkan bahwa perilaku kepemimpin yang berhasil dan efektif apabila pemimpin itu bergaya participative management yang menekankan pada orientasi bawahan dan komunikasi serta dalam organisasi, berpola hubungan yang mendukung (supportive relationship). Dalam konteks ini Likert merancang empat sistem kepemimpinan dalam manajemen:

1. Sistem exploitative authoritative (otoriter dan memeras). Karakter dari sistem ini adalah: pemimpin membuat keputusan dan memerintah bawahannya untuk melaksanakan; sekaligus menentukan standar hasil kerja dan cara pelaksanaannya; kegagalan pencapaian hasil yang ditetapkan mendapat ancaman dan hukuman; pemimpin menaruh kepercayaan kecil sekali terhadap bawahan dan sebaliknya bawahan merasa jauh dan takut sekali dengan atasan.

2. Sistem benevolen authoritative (otoriter yang baik), Karakteristik dari sistem ini adalah: pemimpin masih menentukan perintah, tetapi bawahannya mempunyai kebebasan untuk memberi tanggapan terhadap perintahnya; bawahan diberi kesempatan untuk melaksanakan tugasnya dalam batas-batas yang telah ditetapkan secara rinci sesuai dengan prosedur; bawahan yang 
telah mencapai sasaran produksi yang ditetapkan akan diberi hadiah dan penghargaan.

3. Sistem consultative (konsultasi). Karakteristik dari sistem ini adalah: pemimpin menetapkan sasaran tugas dan memberikan perintahnya setelah mendiskusikan hal tersebut dengan bawahannya; bawahan dapat membuat keputusan sendiri mengenai pelaksanaan tugasnya, tetapi keputusan penting dibuat oleh pemimpin tingkat atas; penghargaan dan ancaman/hukuman digunakan sebagai motivasi terhadap bawahannya; bawahan merasa bebas untuk mendiskusikan hal yang berkaitan dengan pekerjaannya dengan pemimpin; dan pemimpin merasa bahwa bawahan dapat dipercaya untuk melaksanakan tugasnya dengan baik.

4. Sistem participative (partisipasi). Karakteristik dari sistem ini adalah: sasaran tugas dan keputusan yang berhubungan dengan pekerjaan dibuat oleh kelompok; jika pemimpin mengambil keputusan maka keputusan itu diambil setelah memperhatikan pendapat kelompok; motivasi bawahan tidak saja berupa penghargaan ekonomis, tetapi juga berupa suatu upaya agar bawahannya merasakan bagaimana pentingnya mereka serta harga dirinya sebagai manusia yang bekerja; dan hubungan antara pemimpin dan bawahan terbuka, bersahabat, dan saling percaya.

Lebih lanjut Likert menyimpulkan bahwa penerapan exploitative authoritative dan benevolen authoritative akan menghasilkan produktivitas kerja rendah, sedangkan penerapan consultative dan partisipative akan menghasilkan produktivitas kerja yang tinggi. Sehingga jika dilihat dari hasil penelitian yang telah dipaparkan di Bab IV maka dapat diketahui jika perilaku kepemimpinan kolektif-kolegial di pondok pesantren Bahrul Ulum Tambakberas Jombang adalah kepemimpinan kolektif-kolegial yang partisipatif-demokratis, hal ini karena adanya kepercayaan (trust) atas wewenang dan tugas yang diberikan oleh majlis kiai, serta adanya saling berkaitan (connection) antara majlis kiai sebagai lembaga tertinggi, majlis a'wân sebagai lembaga pertimbangan, pengurus harian sebagai pelaksana kebijakan, dan pengurus yayasan sebagai pengelola aset pesantren. Sedangkan untuk kepemimpinan kolektif-kolegial di Pondok Pesantren Mambaul Ma'arif Denanyar Jombang adalah kepemimpinan kolektif-kolegial yang demokratis-konsultatif. Perilaku ini terjadi adanya dominasi kekuasaan dari majelis pengasuh atas kewenangan yang diberikan kepada pengurus harian sehingga kreativitas pengurus harian terbatasi oleh perilaku dan tradisi-budaya 
Devi Pramitha - Kepemimpinan Kolektif di Pondok Pesantren (Studi Multisitus di PP. Tebuireng Jombang, PP. Bahrul Ulum Tambakberas Jombang dan PP. Mambaul Ma'arif Denanyar Jombang)

kepesantrenan, serta tidak adanya lembaga pertimbangan yang khusus. Adapun di Pondok Pesantren Tebuireng Jombang adalah kepemimpinan kolektif mengarah pada gaya kepemimpin partisipatifkonsultatif, hal ini karena memang secara struktur organisasi mengarah pada kepemimpinan tunggal nanmun pada aplikasinya tetap melibatkan banyak pihak terkait.

\section{KESIMPULAN}

Dari berbagai pemaparan data dan hasil analisis di atas dapat peneliti simpulkan yaitu sebagai berikut Kepemimpinan kolektifkolegial sangat cocok untuk diterapkan di pondok pesantren terlebih yang sudah berbentuk yayasan dan termasuk pondok yang besar. Adanya majelis pengasuh yang terdiri dari kiai sepuh sebagaipusat kepemimpinan kolektif di pesantren mempunyai peran-peran strategis dalam proses pengembangan organisasi kepesantrenan dan lembaga pendidikan yang lebih dinamis dan efektif melalui pelibatan semua unsur stakeholders pesantren, yaitu; majelis pengasuh sebagai brand manager, dewan pengawas sebagai auditor internal serta pengurus harian sebagai penerima delegasi (staffing) yang dibantu oleh kepala unit program pendidikan dan kepesantrenan. Adapun tiga model kepemimpinan kolektif-kolegial di pesantren sebagai model kecenderungan dewasa ini di antaranya adalah: (1) partisipatifdemokratis, (2) demokratis-konsultatif, dan (3) partisipatif-konsultatif

\section{DAFTAR PUSTAKA}

Dhofier, Zamakhsyari. 1994. Tradisi Pesantren: Studi tentang Pandangan Hidup Kiai. Jakarta: LP3ES

Dhofir, Syarqawi. 2004. Kekuasaan dan Otoritas Kiai dalam Pondok Pesantren. Surabaya: UNESA

Likert, Rensis. 1967. The Human Organization: Its Management and Value. New York: McGraw-Hill

Rivai, Veithzal. 2013. Islamic Management: Meraih Sukses melalui Praktis Manajemen Gaya Rasulullah secara Istiqomah. Yogyakarta: BPFE

Robbins, Stephen P. 2003. Organizational Behavior. Mexico: Prentice Hall 